\title{
Toys, Décor, and More: Evidence of Hazardous Electronic Waste Recycled into New Consumer Products
}

\author{
Gillian Z. Miller ${ }^{1}$, Meghanne E. Tighe², Graham F. Peaslee², Karla Peña ${ }^{3}$, Jeff Gearhart ${ }^{1}$ \\ ${ }^{1}$ Ecology Center, Ann Arbor, MI, USA \\ ${ }^{2}$ Chemistry Department, Hope College, Holland, MI, USA \\ ${ }^{3}$ Department of Development Sociology, Cornell University, Ithaca, NY, USA \\ Email: gillian@ecocenter.org
}

Received 18 January 2016; accepted 23 February 2016; published 26 February 2016

Copyright (C) 2016 by authors and Scientific Research Publishing Inc.

This work is licensed under the Creative Commons Attribution International License (CC BY).

http://creativecommons.org/licenses/by/4.0/

(c) (i) Open Access

\begin{abstract}
Hazardous chemicals used in electronic and electrical consumer products can re-enter commerce when these products are recycled. The objectives of this study were to 1) identify the possible sources of unexpected chemicals and elements in consumer products, including the use of recycled E-waste plastics and 2) demonstrate bromine detection with nondestructive spectroscopy as an indicator of brominated flame retardants contaminating new products via recycled waste streams. More than 1500 consumer products of diverse types purchased in 2012-2014 were examined using X-ray fluorescence spectroscopy for correlations between bromine and other elements. New electronic products were much more likely than new non-electronics to contain greater than $1000 \mathrm{ppm}$ bromine, consistent with intentionally added flame retardants, while nonelectronic products were more likely to contain between 5 and 100 ppm bromine, suggesting unintentional contamination. A typical suite of elements present in E-waste was found in a majority of plastic products. Two product categories, vinyl floor tiles and beaded necklaces/garlands, were explored in more detail. Specific flame retardant chemicals in bead samples were identified by mass spectrometry and their distribution in beads was studied using scanning electron microscopy and energy dispersive spectroscopy. Five brominated chemicals typically used as flame retardants, including BDE-209, were identified in 50 of 50 Mardi Gras beads analyzed.
\end{abstract}

\section{Keywords}

E-Waste, Recycled Plastic, Flame Retardant, Bromine, XRF 


\section{Introduction}

Many types of post-consumer plastics can be recycled into new products, but electronic and electrical products pose a particular challenge, as they contain a greater diversity of materials and additives than simpler plastics. Electronic and electrical waste (collectively termed E-waste) contains many additives that pose health concerns, including phthalate plasticizers, flame retardants (FRs), and heavy metals [1]. These chemicals can re-enter commerce, potentially increasing human exposure, when these plastics are recycled [2] [3]. Plastics that are separated from E-waste for recycling include polystyrene and polycarbonate polymers from computer and television housings and polyvinyl chloride (PVC) insulation from wires and cables. A recent analysis of recycled E-waste streams in the Netherlands estimated that, of the particular brominated FRs termed POP-BDEs in E-waste (POP means a persistent organic pollutant under the Stockholm Convention), 22\% by mass end up in recycled plastic products [3]. That estimate does not include several other FRs such as BDE-209 (also called deca), which are not currently listed as POPs.

Recent research in Europe showed brominated flame retardants (BFRs) contaminating food-contact items such as kitchen utensils and thermal cups and found evidence that the BFRs originated from recycled E-waste [2] [4]. BFRs have also been found at concentrations suggesting unintentional contamination in children's toys [5] [6]. Bromine detected by XRF has previously been used as a proxy indicator of BFRs in products when other reasonable sources of bromine have been ruled out [7]-[9]. Similarly, chlorine has been used as a proxy indicator of chlorinated FRs in products that do not contain PVC or any other likely source of chlorine. The use of bromine and chlorine as FR proxies was successfully demonstrated in our recent study of children's car seat foams and fabrics [10].

The present study was undertaken to better understand the scale and spread of BFRs and other contaminants from E-waste recycling across diverse consumer products. We analyzed the presence of bromine, chlorine, and metal elements in 1526 new plastic consumer products purchased in the United States in 2012-2014. The products were originally tested as part of a series of healthystuff.org studies measuring elements of concern $(\mathrm{Pb}, \mathrm{Cd}$, $\mathrm{As}, \mathrm{Hg}, \mathrm{Br}, \mathrm{Cl}, \mathrm{Sb}$ ) and the results for individual products were posted online.

The present work includes a new analysis of these aggregated data in which we compared bromine measurements across different categories of plastic products such as toys, baby products, gardening tools, costumes, and floor tiles. See Figure 1 for a complete list of categories. We also carried out more sophisticated analyses on certain products to determine the distribution and identity of BFRs. The study includes many product categories that have not, to our knowledge, previously been examined for E-waste contamination.

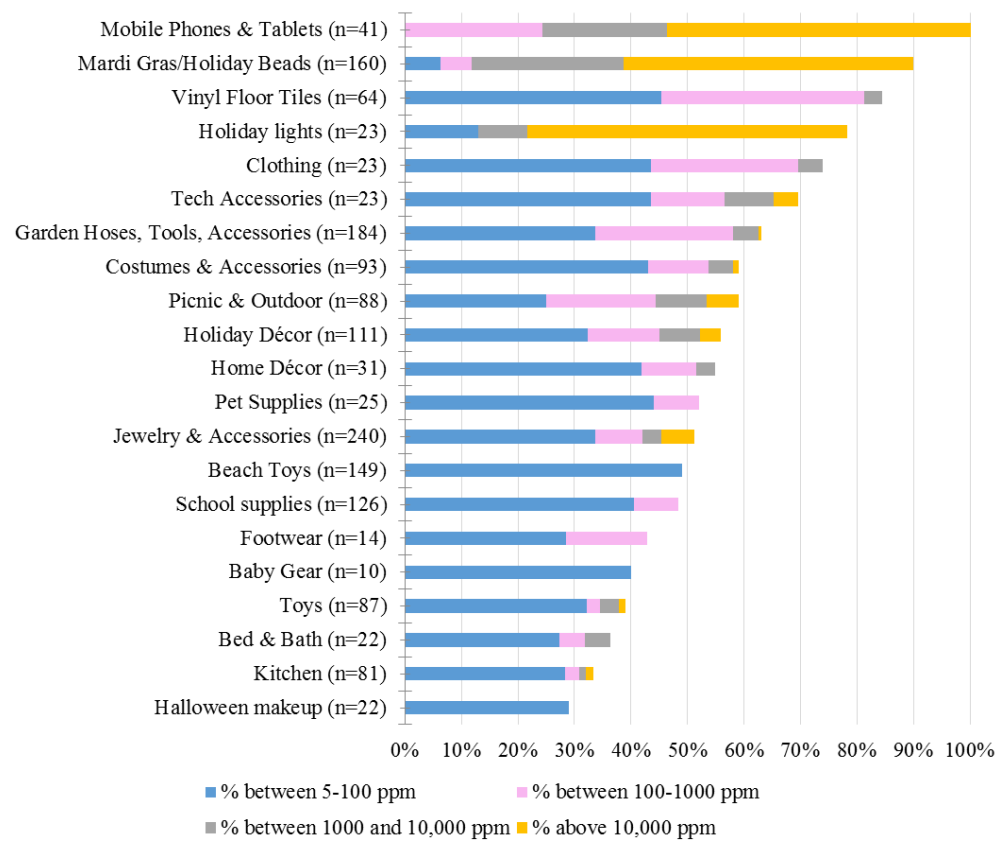

Figure 1. Frequencies of bromine detection in four concentration ranges in different product categories. 


\section{Methods}

\subsection{Sample Selection}

The products were purchased from a variety of retailers and locations in the United States in 2012, 2013, and 2014 and analyzed by high definition X-ray fluorescence (HD XRF) spectroscopy soon after the time of purchase. Items with metal content greater than $5 \mathrm{wt} \%(50,000 \mathrm{ppm})$ were removed from the resulting data set. Wooden items were also removed. The remaining products were polymeric. These were separated into polyvinyl chloride (PVC)—based on chlorine content greater than $9 \mathrm{wt} \%$ - and non-PVC plastics.

Each product was assigned to a category. The categories and number of products in each is given in Figure 1. Both PVC and non-PVC products were then separated into 1) electronic/electrical (E) items, such as holiday lights and charger cables, and 2) non-E items. This separation was necessary because the $\mathrm{E}$ items are likely to contain intentionally added FRs, which we sought to distinguish from FRs arising unintentionally (possibly from E-waste recycled plastics) in non-E consumer products.

\subsection{Instrumental Analysis}

A high definition X-ray fluorescence spectrometer by XOS was used to quantify elements in all product samples. The HD XRF used monochromatic excitation energies of 7, 17, and $33 \mathrm{keV}$ and had a spot size of $1 \mathrm{~mm}$. To obtain an XRF spectrum, the item was placed under the XRF tip and good contact with the component to be tested was verified. Most products were analyzed intact, while some required cutting a piece. For example, vinyl floor tiles were separated into top and backing layers. Thin samples, such as the top layers of floor tiles, were folded multiple times to minimize signal from the substrate underlying the sample.

For all elements of interest except for chlorine, quantification limits with HD XRF were in the low parts per million (ppm) range, with some variation by sample matrix. This limit was determined by the concentration at which two standard deviations of the measured count rate represented no more than $20 \%$ of the mean concentration. Below this limit, measured concentrations were considered qualitative detections. The limit of quantification for chlorine was generally at least several hundred ppm. For bromine, concentrations above 5 ppm were quantitative in almost all cases.

Fifty different Mardi Gras bead samples taken from 47 necklaces were analyzed using liquid chromatography or gas chromatography (depending on the analyte) and mass spectrometry. For mass spectrometry preparation, an organic extraction was performed using $10 \mathrm{~mL}$ of dichloromethane for one to two crushed beads. The beads were filtered through methanol, allowing the dissolved polymers to condense, and the supernatant solution was evaporated to dryness.

Triphenylphosphate (TPP), 1,2-bis(2,4,6-tribromophenoxy)ethane (BTBPE), decabromodiphenyl ether (BDE-209) and decabromodiphenyl ethane (DBDPE) were analyzed by gas chromatography/mass spectrometry (GC/MS) using methods described in [11]. Tetrabromobisphenol A (TBBPA), hexabromocyclododecane (HBCD) and 2,4,6-tribromophenol (2,4,6-TBP) were quantified using an Agilent 5410 triple quadrupole tandem mass spectrometer (LC-MS/MS) coupled with an Agilent 1200 series SL binary pump and Agilent 1200 autosampler. Acetonitrile (ACN) and water (modified with $5 \mathrm{mM}$ acetic acid) were used as the mobile phases, the column oven was $40^{\circ} \mathrm{C}$, the injection volume was $20 \mu \mathrm{l}$ and the flow rate was $400 \mu \mathrm{l} / \mathrm{min}$. Chromatography was achieved under gradient conditions using a C18 column (Agilent Zorbax Eclipse XDB-C18, $4.6 \times 50$ mm, 1.8 $\mu \mathrm{m}$ particle size) preceded by a SecurityGuard Polar-RP $(4 \times 2.0 \mathrm{~mm})$ guard cartridge. Initial conditions were 40:60 water:ACN, held for $1 \mathrm{~min}$, increased to 10:90 over $0.5 \mathrm{~min}$, increased to 5:95 over $4.0 \mathrm{~min}$, held for 0.5 min, returned to initial conditions over $0.25 \mathrm{~min}$, and held for $4.25 \mathrm{~min}$. The mass spectrometer was operated under negative electrospray ionization and data was acquired with multiple reaction monitoring (MRM) conditions using optimized parameters. MRMs monitored were as follows, ${ }^{13} \mathrm{C}-\mathrm{HBCD}: \mathrm{m} / \mathrm{z} 652.9>80.9$, HBCD: $\mathrm{m} / \mathrm{z}$ $640.6>79$ (quantification) and $\mathrm{m} / \mathrm{z} 642.6>79$ (qualification), ${ }^{13} \mathrm{C}$-TBBPA: $\mathrm{m} / \mathrm{z} 554.6>428.5$, TBBPA: $\mathrm{m} / \mathrm{z}$ $542.5>417.7$ (quantification), $\mathrm{m} / \mathrm{z} 542.5>447.8$ (qualification) and $\mathrm{m} / \mathrm{z} 542.5>419.9$ (qualification), ${ }^{13} \mathrm{C}-\mathrm{TBP}$ : $324.8>78.9$, TBP: $328.8>78.9$. Analyte responses were normalized to internal standard responses.

Approximately 12 bead samples from different necklaces were mechanically dissected and imaged by scanning electron microscopy-energy dispersive spectroscopy (SEM-EDS) to map the distribution of brominated FRs. A Hitachi TM-3000 SEM was used with a Bruker EDS system to collect images and elemental concentrations and maps at magnifications between $40 \times$ and $1000 \times$. A Nicolet FTIR spectrometer from Thermo Scientific in attenuated total reflection mode was used to identify the polymer type of several beaded necklaces. 


\section{Results and Discussion}

\subsection{Aggregate Data from Plastic Consumer Products}

Each of the 1526 items in the full sample set was assigned to one of 23 product categories, listed in Figure 1. Within each category, the percentages of products containing bromine 1) between 5 and 100 ppm, 2) between 100 and 1000 ppm, 3) between 1000 and 10,000 ppm, and 4) above 10,000 ppm were calculated. Figure 1 displays the results for each category in descending order of percentage of products containing at least 5 ppm bromine.

The category called Clothing included screen printed images, which were polymeric inks (frequently PVCbased) printed on a tee-shirt, and polyester fabrics. One vinyl belt was included. The category Costumes \& Accessories included polyester fabrics as well as various plastic costume accessories. The Garden category included 56 gardening gloves, 90 hoses, 15 kneeling pads, and 23 garden tools. The Picnic \& Outdoor category included coolers, lawn chairs, tablecloths, plastic parts of grilling utensils, play sprinklers, and other items. Holiday Décor consisted largely of Christmas decorations as well as some Hannukah and Halloween decorations. Home Décor included wall clings, window clings, decorative figurines, and a small number of (non-wooden) furniture pieces. Pet Supplies were largely dog and cat toys as well as leashes and collars. The smallest category was Baby Gear with ten products. The baby products containing at least 5 ppm bromine were a diaper change kit, a vinyl bib, a non-vinyl bib, and a quilted crib pad.

Products with bromine measurements less than 5 ppm were considered to be "free" of bromine for the purposes of this study. As noted, a conservative quantification limit for bromine with our HD XRF is about 5 ppm, although most measurements returning a concentration between 1 and 5 ppm probably do indicate bromine. We chose 5 ppm as a threshold above which we could assert with very high confidence the authenticity of bromine detection.

Mobile phones and tablets, which were dismantled in order to test the inner parts, had the most frequent bromine detection. As illustrated in Figure 1, almost 100\% of phones and tablets had a part with greater than 100 ppm bromine and more than half had a part with at least 10,000 ppm (1 wt\%), presumably due to brominated chemicals intentionally used as FRs. More surprising are the next two categories in Figure 1. Fifty-one percent of beaded necklaces and garlands (Mardi Gras/holiday beads) had bromine greater than 10,000 ppm and 27\% had between 1000 and 10,000 ppm. While vinyl floor tiles did not have such high bromine concentrationsnone above $10,000 \mathrm{ppm}$ - the frequency of bromine detection up to $1000 \mathrm{ppm}$ in the tiles was high: $81 \%$ of the floor tiles contained between 5 and 1000 ppm bromine. Beaded necklaces and floor tiles are not electronic or electrical (E) items and thus are not expected to contain FRs or any other chemical containing bromine, leading us to suspect they are contaminated with BFRs from E-waste. Beads and floor tiles are explored in more detail in Sections 3.2 and 3.3. Of the next three categories in Figure 1, holiday lights and tech accessories (such as charger cables) are electrical in nature and likely to contain added FRs, so their high frequency of bromine is not surprising. The remaining categories contain only non-E items. Taken as a whole, the detection of bromine in such a large portion of non-E products is surprising: $57 \%$ of the 1439 non-E products (i.e. all the categories listed in Figure 1 except for mobile phones/tablets, holiday lights, and tech accessories) contained at least 5 ppm bromine.

Table 1 illustrates the difference in bromine content between non-E and E products. Beaded necklaces/garlands were excluded from Table 1 because of their anomalously high bromine concentrations for a non-E product; all other products were included. More than half of new E products, including both PVC and non-PVC

Table 1. Frequency of bromine detection in different concentration ranges. This table includes all products except beaded necklaces/garlands.

\begin{tabular}{|c|c|c|c|c|}
\hline & \multicolumn{2}{|c|}{ Non-electronic } & \multicolumn{2}{|c|}{ Electronic \& accessories } \\
\hline & PVC items & Non-PVC items & PVC items & Non-PVC items \\
\hline$\%<5 \mathrm{ppm} \mathrm{Br}$ & 35.0 & 52.5 & 14.3 & 15.4 \\
\hline \% between 5 - 100 ppm Br & 52.5 & 31.1 & 28.6 & 5.8 \\
\hline \% between 100 - 1000 ppm Br & 14.3 & 10.1 & 8.6 & 19.2 \\
\hline$\%>1000$ ppm Br & 15.4 & 6.3 & 48.6 & 59.6 \\
\hline Product count (n) & 426 & 853 & 35 & 52 \\
\hline
\end{tabular}


plastics, contained bromine $>1000$ ppm, suggesting intentionally added FRs, while few non-E items had $>1000$ ppm (4\% in PVC; 6\% in non-PVC). Non-E items were more likely (44\% in PVC; 31\% in non-PVC) to contain 5 - 100 ppm bromine, suggesting unintentional contamination.

To test the hypothesis that relatively low levels of bromine in non-E plastic products indicate BFR contamination, we examined the correlations between bromine and other elements typically found in E products and hence E-waste: antimony, cadmium, copper, gold, iron, lead, manganese, rubidium, tin, and zinc. Table 2 shows that among non-E products made of PVC, items containing at least 5 ppm bromine contained, on average, significantly higher concentrations of the other elements than products containing $<5 \mathrm{ppm}$ bromine (termed "Br-free" in Table 2).

The same analysis for non-E, non-PVC products was inconclusive. (This analysis is not shown.) Although nearly all products in this group with bromine $>5 \mathrm{ppm}$ also contained a suite of typical E-waste elements, many products with bromine $<5 \mathrm{ppm}$ contained low concentrations of E-waste elements as well. This result for nonPVC products neither refutes nor supports the hypothesis that low bromine levels in non-E plastic products indicate BFRs, whereas the correlations for PVC products support the hypothesis.

\subsection{Vinyl Floor Tiles}

Vinyl floor tiles purchased in 2014 from five retailers, representing 12 brands, had a thin layer of virgin PVC on top and a much thicker (approximately 2 - $4 \mathrm{~mm}$ ) PVC backing layer. The backing layers were gray or black colored. The use of recycled PVC for the backing layer was confirmed by certain manufacturers via private communications.

Based on XRF analysis, most backing layers contained a suite of metals associated with E-waste, especially gold, lead, strontium, copper, iron, and zinc. In sharp contrast, the top layers contained these elements very infrequently. Table 3 summarizes the frequencies of detection of several elements above relevant thresholds in the top and backing layers of 64 floor tiles. Forty-four percent of the backing layer samples contained at least 100 ppm bromine. The disparity between the top layers and the backing layers as seen in Table 3 suggests that the backing layers may have been sourced from recycled PVC that included a significant portion of E-waste. PVC E-waste largely consists of wire and cable insulation, typically containing added FRs.

Since there is no other likely source for bromine in PVC tile backings, and bromine in these samples is accompanied by other elements associated with E-waste, and several manufacturers confirmed that recycled PVC is used, we posit that the detected bromine indicates BFRs.

Table 2. Elements related to E-waste in non-E PVC products. This table is based on XRF measurements of 844 components of 426 products.

\begin{tabular}{ccc}
\hline & \multicolumn{2}{c}{ Average concentration (ppm) } \\
\cline { 2 - 3 } Elements & PVC items without $\mathbf{B r}(<\mathbf{5 p m})$ & PVC items containing Br ( $>\mathbf{5}$ ppm) \\
\hline Antimony & 34 & 3960 \\
Cadmium & 2 & 413 \\
Copper & 95 & 28 \\
Gold & 1 & 1990 \\
Iron & 183 & 335 \\
Lead & 4 & 64 \\
Manganese & 3 & 35 \\
Rubidium & 2 & 2404 \\
Tin & 417 & 1015 \\
Zinc & 316 & 392 \\
\hline
\end{tabular}


Table 3. Virgin PVC versus recycled PVC in vinyl floor tiles $(n=64)$.

\begin{tabular}{cccc}
\hline Element & Top layer (virgin vinyl) & Backing layer (recycled vinyl) & \\
\hline Gold & 0 & 89 & \% above $10 \mathrm{ppm}$ \\
Bromine & 2 & 44 & \% above $100 \mathrm{ppm}$ \\
Cadmium & 0 & 68 & \\
Lead & 0 & 77 & 38 \\
Manganese & 0 & 96 & $\%$ above $1000 \mathrm{ppm}$ \\
Rubidium & 0 & 45 \\
Strontium & 2 & 85 \\
Antimony & 3 & 93 \\
Copper & 0 & 94 \\
Iron & 5 & 90 & \\
Tin & 35 & 0 & 94 \\
Zinc & &
\end{tabular}

\subsection{Beaded Necklaces and Garlands}

One hundred and sixty beaded necklaces and garlands intended either for Mardi Gras celebrations or for holiday decorations (for example, Christmas tree garlands) were purchased from several retailers between 2012 and 2014. An example is shown in Figure 2, including a bead that has been cut in half to reveal the black plastic inside. A large majority of bead samples contained hazardous metals such as lead, cadmium, and/or arsenic, as well as bromine, chlorine, and/or antimony, the latter three elements suggesting FR chemicals. Antimony trioxide is a FR commonly used as a synergist for halogenated FRs [2].

Fifty-one percent of beaded necklaces and garlands had bromine greater than $10,000 \mathrm{ppm}$ and $27 \%$ had between 1000 and 10,000 ppm. The highest bromine concentration measured was nearly $3 \mathrm{wt} \%$ (30,000 ppm). Even though such high levels of bromine are often associated with intentionally added BFRs, we will argue that the BFRs detected in these beaded products were from recycled plastics, not intentional addition.

Table 4 gives the calculated correlation coefficients R, which measure the linear association between two sets of values, for thirteen elements measured by XRF in the 160 bead samples. The higher the value of $\mathrm{R}$, the lower the p-value, which is the probability that the observed correlation is merely by chance. Bromine content in the beads was strongly correlated with antimony, tin, and gold and moderately correlated with chlorine, arsenic, copper, and cadmium. Other elements associated with E-waste showed relatively weak correlations. The strong correlation of antimony and bromine is significant since antimony trioxide is a flame retardant synergist commonly combined with BFRs. A variety of tin compounds are also used as FRs. The correlations seen in Table 4 suggest a common source of these elements in the beads. We posit that the common source is E-waste plastic.

Chlorine in the beads, which ranged from zero to nearly $5 \mathrm{wt} \%$, was not due to PVC plastic. FTIR analysis of several bead samples indicated that the beads were a mix of acrylonitrile-butadiene-styrene (ABS) plastic and polycarbonate. A PVC spectral signature was not detected. The chlorine detected may be from chlorinated FRs and should be further studied.

Mardi Gras bead samples from 2013 were analyzed by SEM coupled with EDS. Irregular chunks of heavier elements ( $\mathrm{Br}$ and metals) appear as light-colored objects against a darker background of lighter polymer elements (C, H, O) in the SEM images (Figure 3). A representative map of one bead containing high concentrations of bromine according to EDS is shown in Figure 4. The surrounding light-element material did not contain significant bromine. The EDS results for the area within the yellow circle are shown as an inset in Figure 4.

Several FRs were analyzed by LC-MS/MS or GC/MS in 50 beads taken from 47 necklaces. Thirteen of these beads (from 11 necklaces) were analyzed quantitatively with results displayed in Table 5 . The number of samples was limited due to cost and time constraints. The BFRs 2,4,6-TBP, TBBPA, BTBPE, DBDPE, BDE-209 and the non-halogenated TPP were measured in all 13 bead samples. Isomers of another common BFR, HBCD, were not detected. The total concentration of BFRs in each bead is listed in the final column of Table 5 . The concentrations ranged from 28 to $7782 \mathrm{ppm}$. 


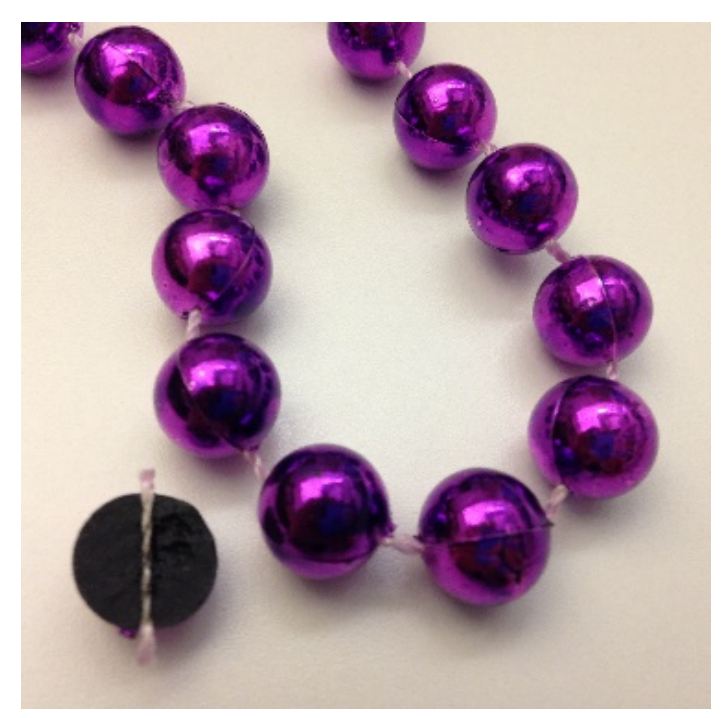

Figure 2. Beaded necklace next to a single bead cut in half.

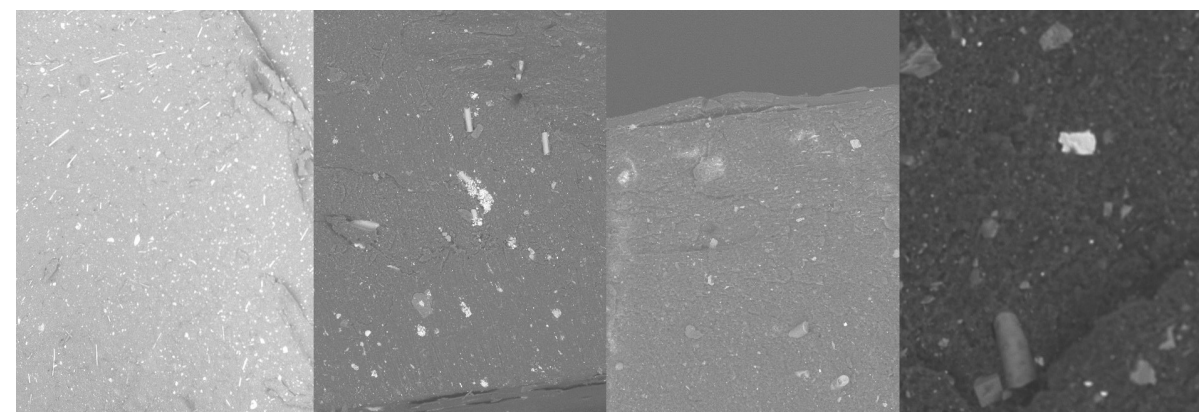

Figure 3. SEM images of Mardi Gras bead samples at (from left) 40×, 250×, 400×, and 1000× magnification.

Table 4. Linear correlation coefficients (R) based on element concentrations in 160 bead products. Shaded red $=$ strong to very strong correlation (between 0.5 and 1 ); shaded gray = weak to moderate correlation (between 0.2 and 0.5 ).

\begin{tabular}{|c|c|c|c|c|c|c|c|c|c|c|c|c|c|}
\hline & $\mathrm{Cl}$ & $\mathrm{Cr}$ & $\mathrm{Cu}$ & $\mathrm{Zn}$ & As & $\mathrm{Br}$ & $\mathrm{Sr}$ & $\mathrm{Cd}$ & Sn & $\mathrm{Sb}$ & $\mathrm{Au}$ & $\mathrm{Pb}$ & $\mathrm{Bi}$ \\
\hline $\mathrm{Cl}$ & 1 & 0.06 & 0.04 & -0.03 & 0.27 & 0.37 & 0.07 & 0.21 & 0.44 & 0.40 & 0.22 & -0.02 & 0.66 \\
\hline $\mathrm{Cr}$ & 0.06 & 1 & 0.13 & 0.20 & 0.08 & 0.04 & 0.09 & 0.05 & 0.20 & 0.15 & 0.03 & 0.51 & -0.01 \\
\hline $\mathrm{Cu}$ & 0.04 & 0.13 & 1 & 0.17 & 0.38 & 0.15 & 0.02 & 0.04 & 0.15 & 0.15 & 0.11 & -0.01 & 0.02 \\
\hline $\mathrm{Zn}$ & -0.03 & 0.20 & 0.17 & 1 & 0.05 & -0.03 & -0.01 & -0.01 & 0.00 & -0.01 & 0.01 & 0.28 & -0.05 \\
\hline As & 0.27 & 0.08 & 0.38 & 0.05 & 1 & 0.42 & 0.08 & 0.21 & 0.35 & 0.33 & 0.26 & 0.01 & -0.15 \\
\hline $\mathrm{Br}$ & 0.37 & 0.04 & 0.15 & -0.03 & 0.42 & 1 & 0.01 & 0.28 & 0.52 & 0.63 & 0.41 & -0.04 & -0.02 \\
\hline $\mathrm{Sr}$ & 0.07 & 0.09 & 0.02 & -0.01 & 0.08 & 0.01 & 1 & 0.02 & 0.08 & 0.03 & 0.49 & 0.02 & -0.05 \\
\hline $\mathrm{Cd}$ & 0.21 & 0.05 & 0.04 & -0.01 & 0.21 & 0.28 & 0.02 & 1 & 0.42 & 0.37 & 0.12 & -0.01 & -0.06 \\
\hline Sn & 0.44 & 0.20 & 0.15 & 0.00 & 0.35 & 0.52 & 0.08 & 0.42 & 1 & 0.93 & 0.26 & -0.03 & 0.00 \\
\hline $\mathrm{Sb}$ & 0.40 & 0.15 & 0.15 & -0.01 & 0.33 & 0.63 & 0.03 & 0.37 & 0.93 & 1 & 0.26 & -0.04 & -0.00 \\
\hline $\mathrm{Au}$ & 0.22 & 0.03 & 0.11 & 0.01 & 0.26 & 0.41 & 0.49 & 0.12 & 0.26 & 0.26 & 1 & 0.02 & -0.07 \\
\hline $\mathrm{Pb}$ & -0.02 & 0.51 & -0.01 & 0.28 & 0.01 & -0.04 & 0.02 & -0.01 & -0.03 & -0.04 & 0.02 & 1 & -0.04 \\
\hline $\mathrm{Bi}$ & 0.66 & -0.01 & 0.02 & -0.05 & -0.15 & -0.02 & -0.05 & -0.06 & 0.00 & -0.00 & -0.07 & -0.04 & 1 \\
\hline
\end{tabular}



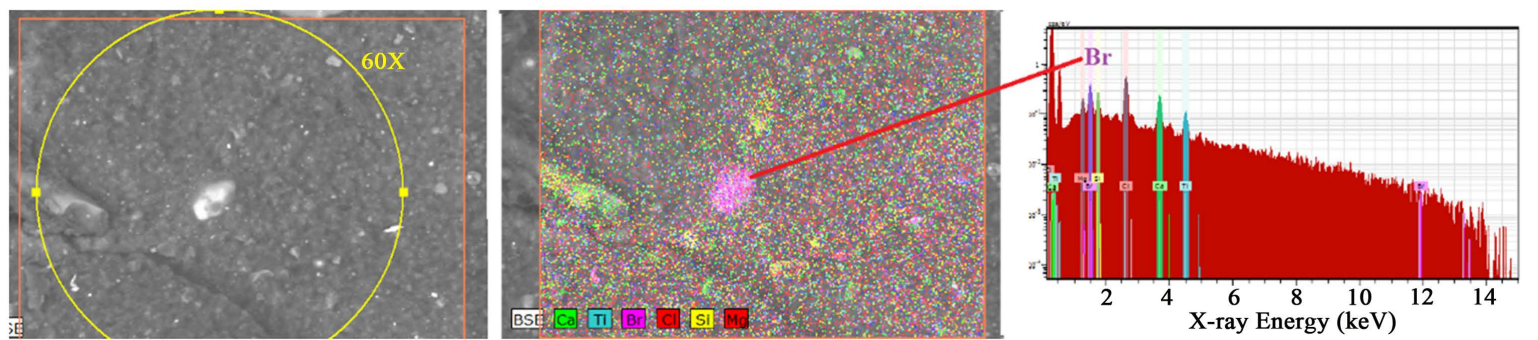

Figure 4. SEM images of a Mardi Gras bead sample at $60 \times$, and an elemental map of the same image showing a bromine inclusion. The X-ray spectrum associated with all the elements visible within the yellow circle is shown as the inset on the right, with the bromine L X-rays identified.

Table 5. FRs quantified by mass spectrometry in 13 beads from 11 beaded necklaces. Units are parts per million. Samples are listed in decreasing order of total measured BFR.

\begin{tabular}{ccccccccc}
\hline Necklace ID & Bead description & $2,4,6-$ TBP & TBBPA & BTBPE & DBDPE & BDE-209 & TPP & Total BFR \\
\hline MG120 & Purple large round bead & 188 & 6664 & 329 & 30 & 570 & 1272 & 7782 \\
MG107 & Green large mask ornament bead & 163 & 4894 & 418 & 476 & 1176 & 503 & 7126 \\
MG107 & Gold large mask ornament bead & 284 & 3282 & 206 & 322 & 1431 & 986 & 5535 \\
MG111 & Gold star bead & 43 & 2959 & 249 & 140 & 786 & 437 & 4181 \\
MG125 & Gold flat bead & 147 & 2991 & 174 & 121 & 559 & 359 & 3992 \\
MG142 & Blue round bead & 238 & 2627 & 201 & 63 & 657 & 962 & 3786 \\
MG139 & Purple round bead & 54 & 1145 & 165 & 238 & 586 & 458 & 2188 \\
MG136 & Purple round bead & 158 & 1256 & 72 & 150 & 327 & 228 & 1964 \\
MG107 & Purple large mask ornament bead & 57 & 1324 & 87 & 123 & 360 & 288 & 1952 \\
MG101 & Green swirl bead & 41 & 540 & 79 & 144 & 294 & 315 & 1098 \\
MG132 & Gold rectangle bead & 7 & 163 & 2 & 25 & 10 & 51 & 207 \\
MG133 & Green rectangle bead & 2 & 37 & 1 & 7 & 7 & 15 & 54 \\
MG131 & Purple rectangle bead & 1 & 21 & 1 & 3 & 2 & 12 & 28
\end{tabular}

The remaining 37 beads were qualitatively analyzed for the same FRs. 2,4,6-TBP, TBBPA, BTBPE, DBDPE, BDE-209, and TPP were positively identified in all 37 beads. Note that the XRF results from 160 bead samples found about $90 \%$ contained at least 5 ppm bromine. This is consistent with the results from the subset of 50 beads analyzed by mass spectrometry. Taken together, the mass spectrometry and SEM-EDS results suggest that BFRs are primarily present in small chunks embedded in the plastic beads. It is reasonable to expect a wide range of BFR content across individual beads if the BFRs come from recycled ABS and/or polycarbonate plastic in the form of small pieces mixed in with the overall plastic used to make the beads. ABS and polycarbonate are common E-waste plastics, used in housings for computers, monitors, and televisions, for example. Such housings are typically made from polymers containing reactive or additive FRs and also may be coated with FR chemicals.

All of the FR chemicals detected in the beads have been used in electronics. 2,4,6-TBP is a wood preservative as well as an intermediate in brominated epoxies [12]. TBBPA is a monomer used to make resins for flameretardant printed circuit boards. It is also used to make brominated polycarbonate plastics. BTBPE has been used since the 1970s in polystyrene, thermoplastics, and resins [13]. DBDPE has been used since the 1990's as a replacement for BDE-209 [14]. BDE-209, or deca, used extensively in products such as television casings, was voluntarily phased out by the end of 2013 by the two U.S. producers. TPP is widely used in many product categories. 
Plastic beaded necklaces and garlands, like many consumer products, are mass produced in Asia. Sources of the plastic feedstocks are unknown. Considering 1) the morphology of the beads, consisting of irregular chunks of high-bromine material embedded in low-bromine plastic, 2) the detection of bromine between 100 and 10,000 ppm in $78 \%$ of bead samples, and 3) the fact that intentionally adding FRs to beaded necklaces would add cost without justification and thus is unlikely, we suggest that E-waste streams containing ABS and polycarbonate plastics from recycled electronics are a major source for these beads. The result is beads containing significant concentrations of multiple toxic metals and flame retardant chemicals, including chemicals that have been banned or voluntarily phased out from commerce, such as deca.

\section{Conclusion}

We quantified bromine and other relevant elements in over 1500 plastic consumer products and argued 1) that bromine detected in the non-electronic products is at least partly due to BFRs and 2) that these FRs are from the inclusion of recycled E-waste plastics. We further examined the backing layers of vinyl floor tiles. The recycled PVC backing layers contained many elements related to E-waste, in sharp contrast to the non-recycled PVC layers on top of the tiles. Finally, we presented additional analyses on beaded necklaces and garlands because those products contained unexpectedly high concentrations of bromine and several other hazardous and E-related elements, including lead. Mardi Gras bead samples contained multiple BFRs, including BDE-209, with evidence that these FRs are concentrated in small chunks within the bead plastic. Rare earth elements were not measured in our samples, but should be included in future work because certain rare earth elements appear to be significantly associated with E-waste [2]. Our results are consistent with related studies by other researchers that have found low concentrations of BFRs, most likely from recycled E-waste, in plastic kitchen utensils and toys [2], [4]-[6]. The present study demonstrates that recycling E-waste plastics puts highly persistent and hazardous chemicals back into a wide range of consumer products that normally would not contain those chemicals. Research is needed on the contribution of these commonly used products to the human body burden of persistent chemicals.

\section{Acknowledgements}

The authors are very grateful to Professor Heather Stapleton and Dr. Craig Butt of Duke University, North Carolina, for carrying out the LC-MS/MS and GC/MS analyses. We thank Vicki Fung (Univ. of Michigan) for compiling data and Holly Groh of Verdi Gras, New Orleans for collecting bead samples. We also thank the John Merck Fund, the Park Foundation and New York Community Trust for funding our work at the Ecology Center.

\section{References}

[1] Robinson, B.H. (2009) E-Waste: An Assessment of Global Production and Environmental Impacts. Science of the Total Environment, 408, 183-191. http://dx.doi.org/10.1016/j.scitotenv.2009.09.044

[2] Puype, F., Samsonek, J., Knoop, J., Egelkraut-Holtus, M. and Ortlieb, M. (2015) Evidence of Waste Electrical and Electronic Equipment (WEEE) Relevant Substances in Polymeric Food-Contact Articles Sold on the European Market. Food Additives and Contaminants Part A, 32, 410-426. http://dx.doi.org/10.1080/19440049.2015.1009499

[3] Leslie, H., Leonards, P., Brandsma, S., van Hattum, A., Janssen, M. and Jonkers, N. (2014) Tracing POP-BDE Routes through Plastic Waste Streams in the Netherlands. Organohalogen, 899.

[4] Samsonek, J. and Puype, F. (2013) Occurrence of Brominated Flame Retardants in Black Thermo Cups and Selected Kitchen Utensils Purchased on the European Market. Food Additives and Contaminants Part A, 30, 1976-1986. http://dx.doi.org/10.1080/19440049.2013.829246

[5] Chen, S.J., Ma, Y.J., Wang, J., Chen, D., Luo, X.J. and Mai, B.X. (2009) Brominated Flame Retardants in Children’s Toys: Concentration, Composition, and Children's Exposure and Risk Assessment. Environmental Science and Technology, 43, 4200-4206. http://dx.doi.org/10.1021/es9004834

[6] Ionas, A.C., Dirtu, A.C., Anthonissen, T., Neels, H. and Covaci, A. (2014) Downsides of the Recycling Process: Harmful Organic Chemicals in Children’s Toys. Environment International, 65, 54-62. http://dx.doi.org/10.1016/j.envint.2013.12.019

[7] Stapleton, H.M., Klosterhaus, S., Keller, A., Ferguson, P.L., Van Bergen, S., Cooper, E., Webster, T.F. and Blum, A. (2011) Identification of Flame Retardants in Polyurethane Foam Collected from Baby Products. Environmental Science and Technology, 45, 5323-5331. http://dx.doi.org/10.1021/es2007462 
[8] Allen, J.G., McClean, M.D., Stapleton, H.M. and Webster, T.F. (2008) Linking PBDEs in House Dust to Consumer Products Using X-Ray Fluorescence. Environmental Science and Technology, 42, 4222-4228. http://dx.doi.org/10.1021/es702964a

[9] Gallen, C., Banks, A., Brandsma, S., Baduel, C., Thai, P., Eaglesham, G., Heffernan, A., Leonards, P., Bainton, P. and Mueller, J.F. (2014) Towards Development of a Rapid and Effective Nondestructive Testing Strategy to Identify Brominated Flame Retardants in the Plastics of Consumer Products. Science of the Total Environment, 491-492, 255-265. http://dx.doi.org/10.1016/j.scitotenv.2014.01.074

[10] Miller, G.Z. and Gearhart, J. (2015) Hidden Passengers: Chemical Hazards in Children’s Car Seats. http://www.ecocenter.org/healthy-stuff/reports/childrens-car-seat-study

[11] Stapleton, H.M., Misenheimer, J., Hoffman, K. and Webster, T.F. (2014) Flame Retardant Associations between Children's Handwipes and House Dust. Chemosphere, 116, 54-60. http://dx.doi.org/10.1016/j.chemosphere.2013.12.100

[12] Howe, P., Dobson, S. and Malcolm, H. (2005) 2,4,6-Tribromophenol and Other Simple Brominated Phenols. World Health Organization Concise International Chemical Assessment Document, 66.

[13] European Food Safety Authority (EFSA) Panel on Contaminants in the Food Chain (2012) Scientific Opinion on Emerging and Novel Brominated Flame Retardants (BFRs) in Food. EFSA Journal, 10, 125.

[14] Egebäck, A.-L., Sellström, U. and McLachlan, M.S. (2012) Decabromodiphenyl Ethane and Decabromodiphenyl Ether in Swedish Background Air. Chemosphere, 86, 264-269. http://dx.doi.org/10.1016/j.chemosphere.2011.09.041 